\title{
O PROGRAMA DE EDUCAÇÃO TUTORIAL COMO FACILITADOR DA IMPLEMENTAÇÃO DAS NOVAS DIRETRIZES CURRICULARES NACIONAIS PARA OS CURSOS DE ENGENHARIA
}

Luiz Tadeu Dias Júnior - luiz.tadeu@engenharia.ufjf.br

Universidade Federal de Juiz de Fora - Faculdade de Engenharia

Rua Espírito Santo, $n^{o} 1290$, apto 301, Centro

36016-200 - Juiz de Fora - Minas Gerais

Renan de Carvalho Pinto - renan.carvalho@engenharia.ufjf.br

Universidade Federal de Juiz de Fora - Faculdade de Engenharia

Rua Itatiaia, $n^{\circ} 390$, apto 203, Monte Castelo

36081-050 - Juiz de Fora - Minas Gerais

Iasmin Ferreira Nery - iasmin.nery@engenharia.ufjf.br

Universidade Federal de Juiz de Fora - Faculdade de Engenharia

Rua Aristóteles Braga, $n^{\circ} 345$, bl 03, apto 502, São Pedro

36037-010 - Juiz de Fora - Minas Gerais

Raquel Rodrigues Bernardes - raquel.rodrigues@engenharia.ufjf.br

Universidade Federal de Juiz de Fora - Faculdade de Engenharia

Rua Doutor Norberto Gerhein, $n^{\circ} 165$, Cerâmica

36080-400 - Juiz de Fora - Minas Gerais

Giovanna Schäfer Bartels - giovanna.schafer@engenharia.ufjf.br

Universidade Federal de Juiz de Fora - Faculdade de Engenharia

Rua Antônio Stephan, $n^{\circ}$ 29, Borboleta

36035-480 - Juiz de Fora - Minas Gerais

Júlia Righi de Almeida - julia.righi@engenharia.ufjf.br

Universidade Federal de Juiz de Fora-Departamento de Transportes e Geotecnia

Rua Monsenhor Gustavo Freire, $n^{\circ} 21$, apto 205, São Mateus

36016-470 - Juiz de Fora - Minas Gerais

Resumo: Esse artigo tem o intuito de mostrar como o Programa de Educação Tutorial (PET) contribui para o desenvolvimento das novas Diretrizes Curriculares Nacionais dos cursos de Engenharia. Para isso são abordados projetos e atividades realizadas pelo PET do curso de Engenharia Civil da Universidade Federal de Juiz de Fora (PET Civil UFJF) e explicitada a forma como desenvolvem competências e impactam diretamente no desenvolvimento e na formação profissional dos participantes. Desse modo, percebe-se o Programa de Educação Tutorial como um agente transformador da graduação em que está inserido, sendo um facilitador e auxiliador no processo de formação do perfil de engenheiro desejado no mercado de trabalho dos dias atuais.

Palavras-chave: Diretrizes Curriculares. Programa de Educação Tutorial. Desenvolvimento de Competências. 


\section{INTRODUÇÃ̃o}

O objetivo das novas Diretrizes Curriculares Nacionais (DCNs) para o curso de graduação em Engenharia, publicadas em 2019, se baseia na formação de um perfil de engenheiro que saiba aplicar as competências adquiridas ao longo da vida acadêmica na resolução de problemas. Tal noção de competência advém da resposta do indivíduo ao cenário no qual está inserido, seja ele a sala de aula ou o ambiente mercadológico, estando relacionada à capacidade de abordar e solucionar situações complexas (ARAVENA-REYES et al., 2005).

De acordo com o Art. $16^{\circ}$ das novas DCNs, os cursos de Engenharia têm o prazo de três anos após a data de publicação para a implementação dessas diretrizes nas Instituições de Ensino Superior - IES (MEC/CNE/CES, 2019b). Assim, uma vez que o teto para a implantação é até 23 de abril de 2022, os alunos que concluírem o curso antes de 2027 (considerando o tempo mínimo de formação de 10 períodos) não teriam desenvolvido as competências solicitadas. Por isso, é necessário entender a realidade de cada IES e encontrar uma ferramenta que auxilie os alunos e egressos do curso a desenvolver habilidades inerentes a essas diretrizes desde o início da graduação.

O Art. $6^{\circ}$, parágrafos $3^{\circ}, 4^{\circ}, 6^{\circ}, 7^{\circ}$ e $12^{\circ}$ das novas DCNs argumentam que a aprendizagem ativa e as atividades baseadas em ensino, pesquisa e extensão são pontos desejáveis no Projeto Pedagógico do Curso (PPC). Tais temáticas estão estritamente ligadas com o propósito do Programa de Educação Tutorial (PET), segundo o Manual de Orientações Básicas (MINISTÉRIO DA EDUCAÇÃO, 2006) e suas atividades. O Programa de Educação Tutorial de Engenharia Civil da Universidade Federal de Juiz de Fora (PET Civil UFJF) atua há 13 anos com base na tríade ensino, pesquisa e extensão, e desenvolve as competências desejáveis nos egressos direta e indiretamente (CARVALHO, et al., 2019a).

As competências desenvolvidas nos egressos têm o intuito de acompanhar a evolução do mercado de trabalho e a área acadêmica. O presente artigo busca inserir o PET Civil UFJF como uma ferramenta auxiliadora no desenvolvimento das competências elencadas pelas DCNs de Engenharia, mesmo antes da sua implantação.

\section{METODOLOGIA}

Este artigo visa expor as novas DCNs e relacioná-las ao protagonismo do aluno no processo de aprendizagem, apresentando os benefícios de direcionar o ensino para aperfeiçoamento de competências.

Posteriormente, será abordado o tempo necessário para a implantação destas diretrizes nas IES e como o PET influencia a formação dos alunos por meio de atividades baseadas em competências alinhadas com as diretrizes.

Por fim, este artigo introduz caminhos a serem trabalhados por meio de atividades desenvolvidas pelo PET Civil UFJF que incitam conceitos importantes para uma formação holística. Busca ainda elencar as respectivas potencialidades, compreendendo os pontos fortes de cada uma e expondo as competências atribuídas aos participantes.

\section{AS DCN'S E AS COMPETÊNCIAS}

Ao analisar as novas DCNs, pode-se afirmar que houve uma mudança de critérios esperados pelos egressos dos cursos de Engenharia ao inserir o aluno como protagonista no processo de aprendizagem. Dessa forma, é esperado que exista uma formação focada em competências, e não apenas em habilidades inerentes ao exercício da profissão. 
As competências a seguir foram levantadas a partir do Art. $3^{\circ}$ e Art. $4^{\circ}$ das novas DCNs de Engenharia (MEC/CNE/CES, 2019b), sendo sintetizadas em 10 principais (Tabela 1). As novas DCNs propõem mudanças no modelo de ensino a fim de aprimorar os cursos atualmente oferecidos e estimular entre os discentes o desenvolvimento de competências, definidas como a articulação de conhecimentos (saber), habilidades (saber fazer) e atitudes (querer fazer), conforme dito por Pereira (2007).

Figura 1 - Competências cujo desenvolvimento foi avaliado.

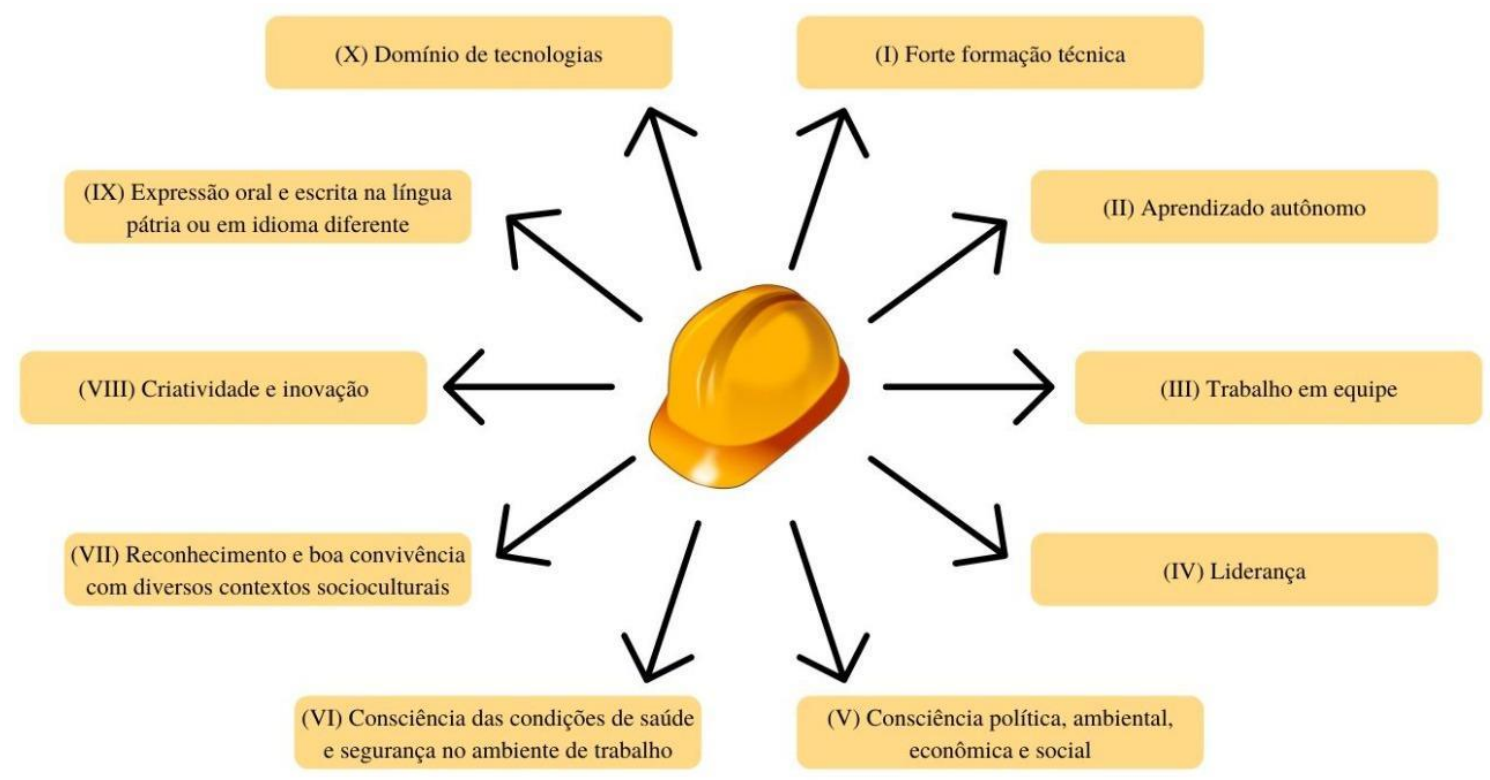

Fonte: Os autores.

\section{COMO O PET INFLUENCIA NO DESENVOLVIMENTO DE COMPETÊNCIAS PARA O ALUNO DE GRADUAÇÃO}

As DCNs apontam que a Engenharia não é distinguida entre as diversas habilitações, sendo tratada como um ramo em que há união de todas elas em prol do engenheiro a ser formado. Ou seja, é necessário que o egresso obtenha um conhecimento multidisciplinar, compreendendo as dificuldades envolvidas no dia a dia do profissional, exigência já pontuada nas antigas diretrizes e agora reforçadas. Deve-se observar que os egressos só estarão formados cinco anos após a implementação das novas diretrizes, portanto os estudos para a criação de um novo perfil de engenheiros devem remeter-se ao futuro, e não apenas ao cenário do momento da sua inserção no meio acadêmico (OLIVEIRA et al., 2019).

Ao observar os prazos estipulados para a concretização dessas diretrizes para os cursos de Engenharia, é importante que todos os alunos, iniciantes ou graduandos, desfrutem dos parâmetros estipulados pela mesma. Além disso, a acelerada expansão dos meios comunicativos e métodos de construção de conhecimento ainda irão cobrar que os novos profissionais se enquadrem no cenário de constante modernização da sociedade.

Para que isso de fato se aplique gradativamente ao longo da graduação, o PET incentiva a participação em atividades estimulantes dessas competências abordadas nas novas DCNs. O PET busca a democratização do conhecimento adquirido ao longo do período de graduação e, em consonância com as competências requeridas pelas novas DCNs, consegue trazer aos discentes uma abordagem diferente de tudo o que é contemplado na sala de aula. 


\section{RESULTADOS}

A seguir serão apresentadas atividades que demonstram o papel do PET Civil UFJF que é aprimorar a educação desenvolvendo certas competências. Tendo isso em vista, o grupo realiza atividades que auxiliam na construção de uma formação completa e holística. Algumas dessas atividades serão descritas a seguir, apresentando a forma como contribuem para o cumprimento das novas diretrizes (Figura 2).

Figura 2 - Quadro resumo das atividades e competências relacionadas a cada uma.

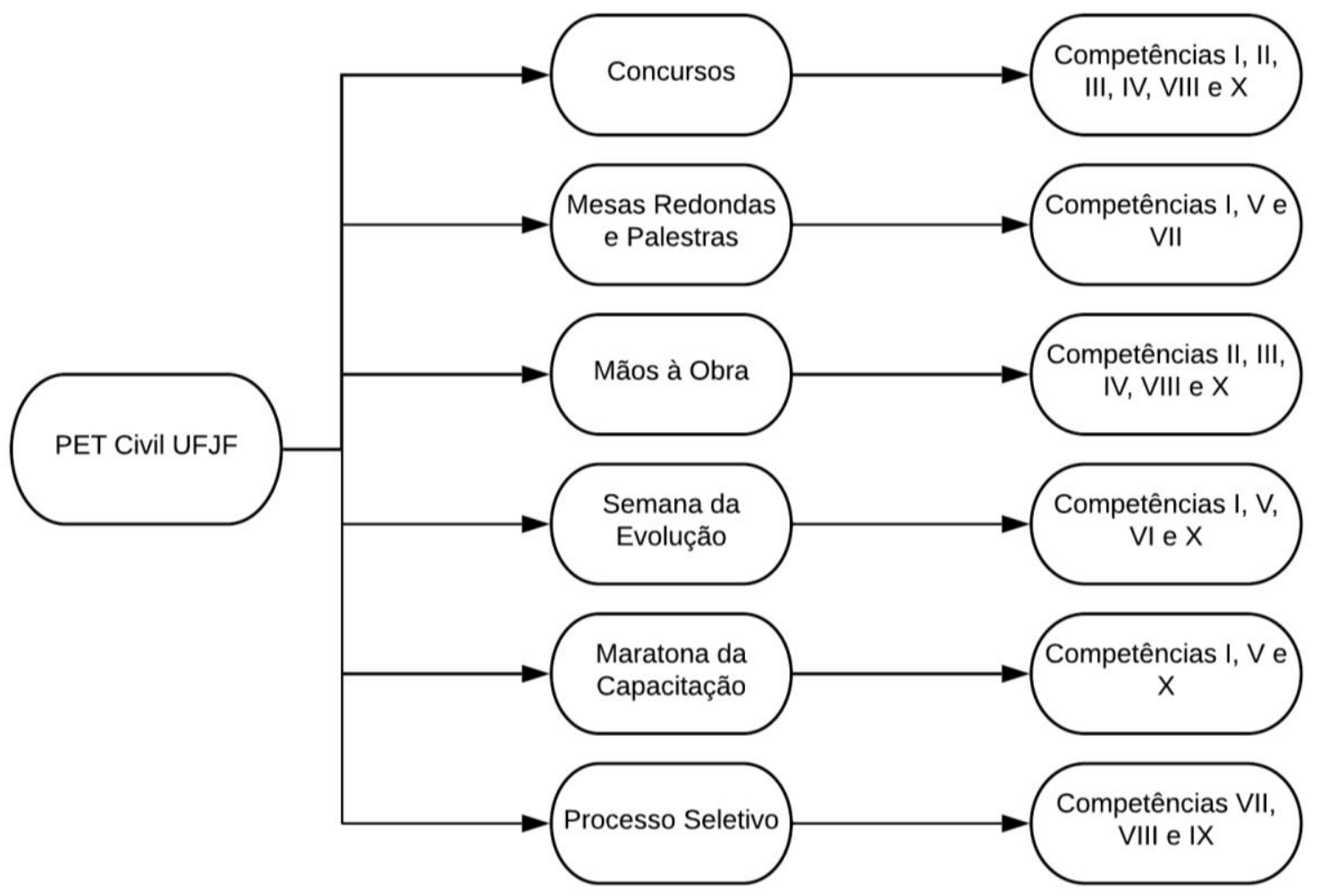

Fonte: Os autores.

\subsection{CONCURSOS}

O PET Civil UFJF realiza concursos, com objetivo de auxiliar os alunos da graduação na prática da Engenharia Civil, através do uso de conceitos aplicáveis e utilizando softwares. Esses eventos são caracterizados por uma competição entre grupos formados pelos estudantes e consistem na simulação de estruturas e seus comportamentos.

São realizados três tipos de concurso: o Mola, Taludes e Pontes. O Concurso Mola consiste na simulação de estruturas (concreto ou metálica) em tamanho reduzido utilizando o Mola Structural Kit ${ }^{\circledR}$. Já no Concurso de Taludes, são representadas obras de terra em escala menor. O Concurso de Pontes possui duas variações: o de papel e o de palitos, os quais consistem na construção de uma ponte utilizando papel, ou palitos de picolé, e cola branca, sendo necessários cálculos de engenharia.

Para que estudantes de todos os períodos possam participar são feitas capacitações de nivelamento que contribuem para a formação técnica dos participantes. Ademais, o aprendizado autônomo é desenvolvido quando são fornecidos materiais de apoio para cada 
um desses concursos e os participantes têm que elevar seu conhecimento além do que é ensinado na graduação.

A formação de grupos para as competições ainda promove o trabalho em equipe em conjunto com uma boa liderança. No caso dos concursos Mola e Pontes de Papel, os integrantes da atividade ainda tem um contato com novas tecnologias, como o Mola Structural $\mathrm{Kit}^{\circledR}$ e softwares de engenharia para modelagem de estruturas. Assim, a realização de um concurso promove o desenvolvimento de muitas competências, as quais atualmente são necessárias para qualquer profissional que almeja possuir uma boa competitividade no mercado de trabalho (SCARTON et al., 2017).

\subsection{MESAS REDONDAS E PALESTRAS}

Pensando em responsabilidade social, o PET Civil UFJF também desenvolve atividades tais como o Com Ciência Negra, o Médicos da Construção, a Semana da Mulher e o Para Além da Catástrofe. O Com Ciência Negra consistiu em uma mesa redonda composta por discentes, docentes e até mesmo indivíduos fora do meio acadêmico. Essas pessoas vivenciam o racismo e, nesse dia, foi discutida a atuação dos pretos no meio científico. Já o Médico das Construções foi uma apresentação envolvendo uma arquiteta e uma engenheira de perícia em obras. Essas mulheres ressaltaram dificuldades por estarem sujeitas ao sexismo e, no caso da engenheira, ainda foi relatado obstáculos que a mesma encontrou devido ao racismo.

A Semana da Mulher é uma semana onde o grupo destaca mulheres bem-sucedidas e traz uma reflexão sobre a desigualdade de gênero. Dessa forma, são desenvolvidos nos participantes além de consciência política, econômica e social, o reconhecimento sociocultural.

Além disso, como outra alternativa para complementar a formação técnica dos estudantes, o PET Civil UFJF realizou o Para Além da Catástrofe. O evento foi executado em parceria com outros três núcleos: EsF (Engenheiros sem Fronteiras - Núcleo Juiz de Fora), NETEC (Núcleo de Estudo e Projetos em Educação e Tecnologia) e IEEE (Instituto de Engenheiros Eletricistas e Eletrônicos). Nesse dia, foi realizado um conjunto de palestras em que foi possível compreender as causas e consequências do rompimento de uma barragem de rejeito em Brumadinho - Minas Gerais, considerando diferentes opiniões. Dessa forma, além de conceitos técnicos, foram discutidas distintas realidades sociais, promovendo o desenvolvimento da consciência ambiental nos participantes.

\subsection{PROCESSO SELETIVO}

Com intuito de melhorar a forma de recrutamento de membros realizada até 2019, o PET Civil UFJF adaptou as etapas do processo de seleção, inserindo a chamada Experiência PET, que tem duração de duas semanas. Na fase em questão os candidatos são divididos em grupos para que desenvolvam juntos uma nova atividade que se enquadre na filosofia do programa. Dessa forma, são desenvolvidas e avaliadas competências relacionadas ao trabalho em equipe e à liderança.

Os grupos são formados através de uma ferramenta psicológica baseada no livro do Dr. Willian Mouton Marston "Emotion of normal people", denominada DISC. Esse instrumento auxilia no conhecimento acerca do perfil comportamental das pessoas, que pode variar entre dominante, influente, estável e conforme, como ilustrado na Figura 3. Com o perfil comportamental dos candidatos, aliado à diversidade encontrada no curso de 
Engenharia Civil da UFJF, permite-se a formação de grupos heterogêneos e que haja reconhecimento e boa convivência entre diversos contextos socioculturais.

Figura 3 - Relatório DISC.

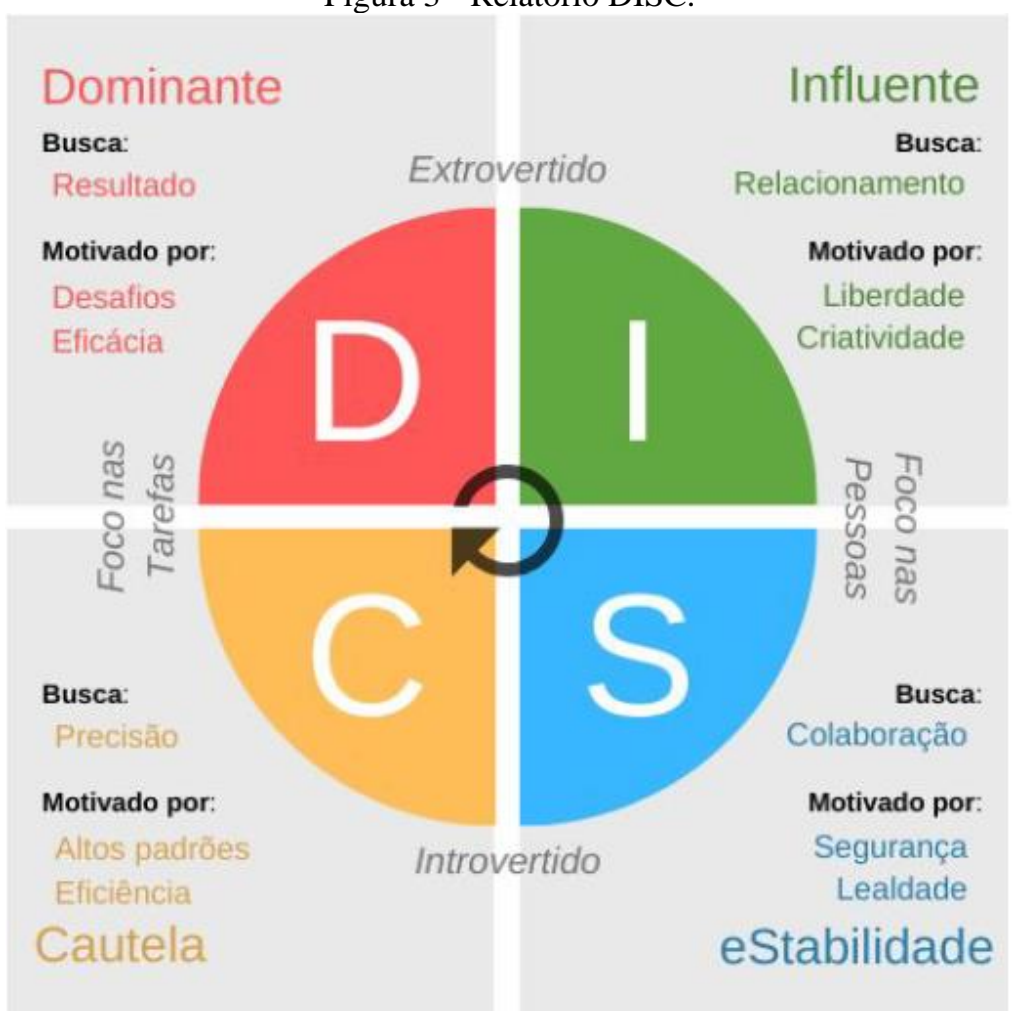

Fonte: Adaptado de: https://www.itu.com.br/artigo/quem-e-este-tal-relatorio-disc-20180126 Acessado em: 23 jun. 2020.

\subsection{MÃOS À OBRA}

A atividade Mãos à Obra é uma iniciativa do PET Civil UFJF que objetiva a conciliação de teoria e prática no que tange às etapas de concepção de uma edificação. Como produto final espera-se obter um plano residencial completo, compreendendo, portanto, os diversos projetos de engenharia necessários para a elaboração de um empreendimento real. Além disso, a área construída deve ser pensada dentro dos preceitos de acessibilidade e sustentabilidade (CARVALHO et al., 2019a).

Essa atividade foi desenvolvida por um ano pelos petianos, a fim de identificar possíveis problemas e estudar as melhores formas de transmiti-la para os estudantes da graduação. Assim, o projeto está sendo planejado para funcionar como um concurso em sua próxima edição, de forma que todos os estudantes do curso de Engenharia Civil tenham a oportunidade de se envolver.

A ideia é formar grupos que irão trabalhar durante um período (a ser definido) na concepção e execução dos diversos projetos, a saber: arquitetônico, estrutural, elétrico, hidrossanitário e de combate e prevenção a incêndio, além da elaboração de manual do proprietário, memoriais descritivos, entre outros.

É notório o desenvolvimento de competências na execução dessa atividade, uma vez que os estudantes desenvolvem o trabalho em equipe e a liderança. Além disso, exercem o aprendizado autônomo quando submetidos à concepção e desenvolvimento de projetos nos mais diversos softwares utilizados na engenharia, tendo contato com novas tecnologias. 
Outros pontos também trabalhados são a conscientização sobre aspectos sociais e ambientais, a percepção da importância da interdisciplinaridade e a competência de solucionar problemas de engenharia através da aplicação da teoria em um cenário prático. Considerando ainda a confecção de documentos, como o manual do proprietário, memoriais e apresentação final dos projetos, vê-se o possível aperfeiçoamento das comunicações escrita e oral.

\subsection{SEMANA DA EVOLUÇÃO}

A Semana da Evolução é um evento que acontece durante uma semana e tem como intuito levar aos participantes o acesso a conhecimentos não desenvolvidos em sala de aula nos cursos de graduação. O evento acontece uma vez ao ano e conta com minicursos, palestras e visitas técnicas.

Os minicursos ofertados incluem aprendizados de diversas áreas como marketing, design gráfico, finanças, além de softwares de engenharia. Essa diversidade proporciona aos alunos uma bagagem de conhecimentos que não estão na grade curricular obrigatória da UFJF, contribuindo assim para uma forte formação técnica e domínio de tecnologias.

Intercalado aos minicursos, acontecem palestras com temas relacionados a Engenharia Civil e a assuntos diversos. Alguns temas que já foram abordados incluem empreendedorismo, oratória, a presença das mulheres na engenharia, sustentabilidade, inovação em grandes empresas e conhecimentos específicos de áreas da engenharia. Sendo assim, esses momentos contribuem ativamente para uma forte formação técnica dos estudantes, além do desenvolvimento da consciência política, ambiental, econômica e social.

As visitas técnicas vêm com o intuito de ampliar a consciência das condições de saúde e segurança no ambiente de trabalho, uma vez que as disciplinas da faculdade, em sua maioria, não promovem esse tipo de atividade. Os locais a serem visitados incluem obras em andamento, concreteiras, barragens e pedreiras. Os percursos são conduzidos por profissionais capacitados que explicam como funcionam os procedimentos de segurança e a qualidade da empresa ou empreendimento.

\subsection{MARATONA DA CAPACITAÇÃO}

A Maratona da Capacitação foi uma atividade desenvolvida no período de isolamento social que aconteceu no ano de 2020 em decorrência da pandemia da COVID-19. A atividade consistiu em fornecer cursos online e gratuitos, sendo ministradas doze capacitações ao público geral, com conteúdos variados.

As capacitações incluíram conhecimentos sobre gestão de projetos, escrita de trabalhos acadêmicos e marketing, utilizando softwares como Photoshop, OBS Studio, MS Project e Camtasia. Esses minicursos estimularam o desenvolvimento de uma formação técnica mais completa dos participantes, além de terem incentivado e desenvolvido o domínio de tecnologias muito úteis na vida de um egresso da graduação de engenharia. Além disso, foi fornecida uma capacitação sobre compostagem, mostrando os benefícios da prática e ensinando aos participantes como montar sua própria composteira. Sendo assim, a Maratona da Capacitação também conseguiu desenvolver nos alunos uma consciência ambiental.

Após várias capacitações, os inscritos foram introduzidos à alguns softwares e aos conhecimentos gerais apresentados. Assim, foi possível aumentar sua gama de experiência 
bem como os hard e soft skills. Foram impactados 764 alunos de Engenharia Civil, comprovando a atuação eficaz do PET Civil UFJF no desenvolvimento das novas DCNs.

\section{CONCLUSÃO}

O intuito do Programa de Educação Tutorial é melhorar a graduação baseando-se na tríade acadêmica (ensino, pesquisa e extensão), pilares do ensino superior no Brasil, e está intrínseco à nova abordagem das novas Diretrizes Curriculares Nacionais. Isso é percebido através do desenvolvimento de competências através de atividades realizadas que impactam a comunidade discente dentro da sua esfera de influência. A atualização do processo de aprendizagem pode acontecer de maneira acelerada se existir o auxílio do PET Civil UFJF.

Tomando esse grupo PET como suporte para a implantação indireta das novas DCNs (uma vez que as atividades realizadas pelo segmento não são obrigatórias e nem estão inseridas no PPC), o desenvolvimento do novo perfil do egresso e a dinamização da aprendizagem baseada no protagonismo do aluno pode se tornar uma realidade próxima. $\mathrm{O}$ desenvolvimento de competências pelos estudantes aconteceria em um prazo menor do que o previsto pela legislação, sem perder a excelência intrínseca ao regulamento.

O PET Civil UFJF deve ser um aliado da coordenação do curso durante e após a implementação das DCNs serem aplicadas. Assim, sugere-se que existam maiores incentivos para a criação desse programa nas diversas Instituições de Ensino Superior no país.

\section{REFERÊNCIAS BIBLIOGRÁFICAS}

ARAVENA-REYES, J. O Conceito de Engenharia à Luz do Conselho Profissional: por uma Crítica Filosófica do Ensino de Engenharia. Revista Eletrônica Engenharia Viva, v. 1, p. 31 46, 2015.

MINISTÉRIO DA EDUCAÇÃO. Programa de Educação Tutorial - PET: Manual de Orientações Básicas. Secretaria de Educação Superior, Departamento de Modernização e Programas da Educação Superior, Coordenação Geral de Relações Acadêmicas de Graduação. 2006. $25 \mathrm{f}$.

CARVALHO, F. A. et al. A Importância Da Etapa "Seminário" No Processo Seletivo XXIV Encontro Nacional dos Grupos PET (ENAPET), 2019b - Rio Grande do Norte, Natal.

CARVALHO, Y. M. et al. O Programa de Educação Tutorial como agente transformador e modulador de competências de um engenheiro. In: XLVII Congresso Brasileiro de Educação em Engenharia e II Simpósio Internacional de Educação em Engenharia da ABENGE, 2019, Fortaleza - CE. Anais... Fortaleza: ABENGE, 10 p., 2019a.

MARSTON, W. M. “Emotional of Normal People”, 2007 Primeira Edição em Português.

MEC/CNE/CES. Resolução $n^{\circ}$ 2, de 24 de abril de 2019. Institui as Diretrizes Curriculares Nacionais do Curso de Graduação em Engenharia. Diário Oficial da União, 80 ed., seção 1, p. 43, $2019 b$.

OLIVEIRA, V. F. Evolução do curso de Engenharia no Brasil. In: OLIVEIRA, V. F. (org.). A Engenharia e as novas DCNs: oportunidades para formar mais e melhores engenheiros. 1. ed. Rio de Janeiro: LTC, p. 8-32, 2019. 
PEREIRA, M. A. C. (2007). Competência para o Ensino e a Pesquisa: um survey com docentes de Engenharia Química. Tese (Doutorado em Engenharia da Produção). Universidade de São Paulo- USP.

SACARTON, L. O. et al. II Concurso Mola. In: XXII Encontro Nacional dos Grupos PET (ENAPET), 2017 - Brasília Distrito Federal.

\title{
THE TUTORIAL EDUCATION PROGRAM AS A FACILITATOR FOR THE IMPLEMENTATION OF THE NEW DCN'S IN ENGINEERING COURSES
}

\begin{abstract}
This article aims to show how the Tutorial Education Program (PET) contributes to the development of new National Curriculum Guidelines for Engineering courses. To this end, projects and activities carried out by PET of the Civil Engineering course at the Federal University of Juiz de Fora (PET Civil UFJF) are planned and explained in order to develop skills and directly impact the development and professional training of the participants. In this way, the Tutorial Education Program is perceived as a transforming agent of the undergraduate course that is inserted, being a facilitator and an assistant in the process of training the profile of the preferred engineer in the current job market.
\end{abstract}

Keywords: Curricular Guidelines. Tutorial Education Program. Skills Development. 